OPEN ACCESS

Edited by:

Tianmu Chen,

Xiamen University, China

Reviewed by:

Hui Liu,

Yunnan Institute of Parasitic

Diseases, China

Ying Liu,

Henan Provincial Center for Disease control and Prevention, China

*Correspondence: Jianhai Yin

yinjh@nipd.chinacdc.cn

Canjun Zheng

zhengcj@chinacdc.cn

Specialty section:

This article was submitted to Infectious Diseases - Surveillance,

Prevention and Treatment, a section of the journal

Frontiers in Public Health

Received: 06 February 2021 Accepted: 25 February 2021 Published: 18 March 2021

Citation:

Wang L, Yin J, Zheng C, Smith SJ,

Ngegba E, Huang $X$, Kamara A, Chen X, Wang X, Luo W and Kan B

(2021) A Household-Based

Cross-Sectional Survey of Knowledge, Awareness and Practice Regarding Malaria in Western Area Rural District, Sierra Leone.

Front. Public Health 9:664971. doi: 10.3389/fpubh.2021.664971

\title{
A Household-Based Cross-Sectional Survey of Knowledge, Awareness and Practice Regarding Malaria in Western Area Rural District, Sierra Leone
}

\author{
Lili Wang ${ }^{1}$, Jianhai Yin ${ }^{2 *}$, Canjun Zheng ${ }^{3 *}$, Samuel Juana Smith ${ }^{4}$, Esther Ngegba ${ }^{1}$, \\ Xiaoxia Huang ${ }^{5}$, Anitta Kamara ${ }^{4}$, Xia Chen ${ }^{6}$, Xu Wang ${ }^{2}$, Wei Luo ${ }^{7}$ and Biao Kan ${ }^{6}$ \\ ${ }^{1}$ Center for Global Public Health, Chinese Center for Disease Control and Prevention, Beijing, China, ${ }^{2}$ National Institute of \\ Parasitic Diseases, Chinese Center for Disease Control and Prevention, Chinese Center for Tropical Diseases Research, \\ Shanghai, China, ${ }^{3}$ Division of Infectious Diseases, Chinese Center for Disease Control and Prevention, Beijing, China, \\ ${ }^{4}$ National Malaria Control Program, Ministry of Health and Sanitation, Freetown, Sierra Leone, ${ }^{5}$ National Institute for Viral \\ Disease Control and Prevention, Chinese Center for Disease Control and Prevention, Beijing, China, ${ }^{6}$ National Institute for \\ Communicable Disease Control and Prevention, Chinese Center for Disease Control and Prevention, Beijing, China, \\ ${ }^{7}$ National Center for AIDS/STD Control and Prevention, Chinese Center for Disease Control and Prevention, Beijing, China
}

Sierra Leone is a highly endemic area for malaria, and the implementation of the National Malaria Strategic Plan (2016-2020) has reached its midpoint in 2018. To provide more specific guidance for interventions in the future, a household-based cross-sectional survey was conducted to elucidate the knowledge, awareness and practices regarding malaria and malarial control measures among the general public. Three communities (Grafton, Jui, and Kossoh) in the Western Area Rural District that were in close proximity to Sierra Leone's capital city of Freetown were included. Households were randomly selected and interviewed with a structured questionnaire covering malaria infection, diagnosis, treatment and prevention, as well as knowledge of malaria prevention. As a result, a total of 262 qualified questionnaires were included. The average cost for meals per day is $\sim 30,000$ Leones in each household. The rate of awareness, indicated by reporting having heard of malaria, was 98.1\% (257/262), and 86.6\% (227/262) of the respondents knew that mosquito bites are the main route of transmission. In addition, $80.9 \%(212 / 262)$ of the respondents sought health advice or treatment for the illness, and a similar percentage of respondents had been tested for malaria, mostly with rapid diagnostic tests (RDTs). A high demand for long-lasting insecticidal nets (72.1\%) matched the serious shortage $(61.8 \%, 162 / 262)$, and of the households that reported a lack of nets, 66 had children younger than 5 years old. In conclusion, public awareness of malaria prevention is high, based on this survey, although there was a limited use of preventive measures in these three communities and the malaria burden was still high. Therefore, the public's knowledge of malaria should be sustained and reinforced, and the distribution and use of malaria prevention measures should be promoted to supprt the achievement of the planned objectives.

Keywords: malaria, KAP survey, Western Area Rural District, Sierra Leone, national malaria strategic plan 


\section{INTRODUCTION}

Malaria is endemic in Sierra Leone; the entire population is at risk of exposure because Sierra Leone is an area of stable malarial endemicity, and almost cases were infected with Plasmodium falciparum (1). Sierra Leone's high malaria disease burden accounted for $\sim 48 \%$ of outpatient morbidity and $\sim 38 \%$ of mortality in children younger than 5 years according to the national Malaria Indicator Survey conducted in 2016 (2). Although significant progress with regard to reducing mortality has been made, it is still a major public health concern. The control of malaria remains a priority in the national health agenda of Sierra Leone.

A multipronged strategy to control malaria, including vector control interventions, diagnostic testing, treatment with quality-assured artemisinin-based combination therapies, and standardized case management training manuals for community and facility treatment providers, has been developed and implemented in Sierra Leone based on the World Health Organization (WHO) recommendations (3). The goals are for $80 \%$ of the population to have appropriate levels of knowledge and uptake/practice of malaria prevention and management strategies, all the at-risk population to have access to the appropriate preventive interventions, $80 \%$ of individuals with

TABLE 1 | The distribution of medical sectors people seeking health advice or treatment in the three communities in the Western Area Rural District, Sierra Leone, 2018.

\begin{tabular}{lcccc}
\hline Medical sector & \multicolumn{3}{c}{ Community } & Total \\
\cline { 2 - 4 } & Grafton & Jui & Kossoh & \\
\hline Public sector only & 68 & 29 & 56 & 153 \\
Private medical sector only & 15 & 5 & 23 & 43 \\
Both sectors & 2 & 10 & 3 & 15 \\
Don't answer & 1 & 0 & 0 & 1 \\
Total & 86 & 44 & 82 & 212 \\
\hline
\end{tabular}

suspected malaria cases to have access to confirmatory diagnostic testing, and all individuals with malaria to receive effective treatment by 2018, according to the current Sierra Leone National Malaria Strategic Plan (2016-2020) (SL-NMSP) (3).

The awareness of malaria symptoms, transmission, prevention and treatments is closely related to the implementations of malaria control programs (4-6). A knowledge, awareness and practices (KAP) survey about malaria could help policy makers better understand the current situation and guide malaria control strategies. Therefore, this study is conducted to determine the knowledge, awareness and practices regarding malaria and its control measures in the general public through a household-based survey at the midpoint of the implementation of the SL-NMSP.

\section{MATERIALS AND METHODS}

\section{Study Site}

Three communities (Grafton, Jui, and Kossoh) in Western Area Rural District within close proximity to Sierra Leone's capital city Freetown were included in this household-based survey on malaria. This district is home to a very religiously and ethnically diverse population. Grafton is a trade center. Jui and Kossoh are neighborhood towns. Kossoh town is surrounded by a large forest reserve, and its major industries are farming and coal mining.

\section{Participants, Questionnaire, and Data Collection}

A total of 300 households in the three designated communities were randomly selected as survey respondents using a cluster sampling design. One adult member from each selected household was interviewed with a structured questionnaire covering demographic information, economic status, basic knowledge of malaria, and malaria prevention and control practices. When medicines were discussed, packages of various drugs were displayed to the participants.

The survey was conducted in collaboration with the National Malaria Control Program of the Ministry of Health and

TABLE 2 | The detail of public or private medical sectors people selected for health care seeking in the three communities in the Western Area Rural District, Sierra Leone, 2018.

\begin{tabular}{|c|c|c|c|c|c|c|c|c|c|c|c|c|c|c|}
\hline 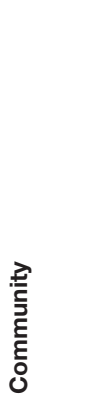 & \multicolumn{6}{|c|}{ Public medical sectors } & \multicolumn{8}{|c|}{ Private medical sectors } \\
\hline Grafton & 38 & 14 & 11 & 3 & 4 & 70 & 9 & 0 & 0 & 0 & 1 & 5 & 2 & 17 \\
\hline Jui & 37 & 1 & 1 & 0 & 0 & 39 & $2^{*}$ & 1 & 1 & $10^{\star}$ & 2 & 0 & 0 & 16 \\
\hline Kossoh & 40 & 12 & 2 & 3 & 2 & 59 & $14^{*}$ & 0 & 0 & $6^{*}$ & 7 & 0 & 0 & 27 \\
\hline
\end{tabular}

*There was one respondent seeking advice or treatment both in the private sectors of private hospital and Mission/Faith-based Clinic in each community. 
TABLE 3 | Malaria diagnosis and anti-malarial medicine taking in the three communities in the Western Area Rural District, Sierra Leone, 2018.

\begin{tabular}{lccc}
\hline Question and answer & & Community & Total \\
\cline { 2 - 4 } & Grafton & Jui & Kossoh
\end{tabular}

1. When you and your family suspected you were infected with malaria, did you always go to see a health worker/doctor?

\begin{tabular}{|c|c|c|c|c|c|}
\hline Yes & 92 & 40 & 89 & 221 & $84.4 \%$ \\
\hline No & 12 & 1 & 7 & 20 & $7.6 \%$ \\
\hline Don't answer & 4 & 6 & 11 & 21 & $8.0 \%$ \\
\hline \multicolumn{6}{|l|}{ 1.1 How often? } \\
\hline Every time & 45 & 6 & 45 & 96 & $43.4 \%$ \\
\hline Most of time & 33 & 29 & 20 & 82 & $37.1 \%$ \\
\hline Seldom & 11 & 4 & 11 & 26 & $11.8 \%$ \\
\hline Only when they showed & 3 & 1 & 13 & 17 & $7.7 \%$ \\
\hline
\end{tabular}

severe condition

2. When you or any member of your family suspected that they had malaria, did the health worker/doctor conduct a malaria test?

$\begin{array}{lcc}\text { Yes } & 88 & 4 \\ \text { No } & 16 & 2 \\ \text { Don't answer } & 4 & 1\end{array}$

3. Did the Doctor/health worker explain to you the test to be done?

$\begin{array}{lcc}\text { Yes } & 64 & 25 \\ \text { No } & 27 & 4 \\ \text { Don't remember } & 9 & 17 \\ \text { Don't answer } & 8 & 1\end{array}$

$\begin{array}{cc}44 & 78 \\ 2 & 1 \\ 1 & 16\end{array}$

78
13

16

25

$4 \quad 26$

$17 \quad 5$

4. What type of test did they say they were going to perform?

RDT

Microscopy

Don't remember

$\begin{array}{cc}57 & 17 \\ 2 & 1 \\ 41 & 27 \\ 8 & 2\end{array}$

121

Don't answer

$\begin{array}{cc}17 & 69 \\ 1 & \\ 27 & \\ 2 & 28\end{array}$

5. When you and your family were infected with malaria, did you take the anti-malarial medicine?

Every time

Most of time

54

Seldom

37

Never

Only when they showed

severe condition

Don't answer

6. What anti-malarial medicines did you take?

Sp/Fansidar

Combination with

Artemisinin

Artesunate+Lumafantrine

Artesunate+Amodiaquine

Amodiaquine

Quinine

Others: specify

Don't answer

4
2
$58^{\#, \&, @}$
$19^{\#, @}$
$6^{\Phi}$
0
$29^{\&, @, \Phi}$

7. When did (NAME(S)) take the anti-malarial medicine?

Same day after fever

Next day after fever

Two day after fever

Three or more day after

fever

Don't know

Don't answer

6

37

3

0

0

\section{1}

$2^{*}$

1

$32^{*}, \$, \%$

14

$2^{\$}$

$1 \%$

0

0

$44 \quad 74$

$3 \quad 8$

0

0

0

0
210

31

21

144

57

31

30

143

5

76

38

108

94

26

2

15

17

6

3

151

54

9

2

39

18

210

24

0

9

2

17
$80.2 \%$

$11.8 \%$

$8.0 \%$

$55.0 \%$

$21.8 \%$

$11.8 \%$

$11.5 \%$

$54.6 \%$

$1.9 \%$

$29.0 \%$

$14.5 \%$

$41.2 \%$

$35.9 \%$

$9.9 \%$

$0.8 \%$

$5.7 \%$

$6.5 \%$

$2.3 \%$

$1.1 \%$

$57.6 \%$

$20.6 \%$

$3.4 \%$

$0.8 \%$

$14.9 \%$

$6.9 \%$

$80.2 \%$

$9.2 \%$

$0.0 \%$

$3.4 \%$

$0.8 \%$

$6.5 \%$ 
TABLE 3 | Continued

\begin{tabular}{|c|c|c|c|c|c|}
\hline \multirow[t]{2}{*}{ Question and answer } & \multicolumn{3}{|c|}{ Community } & \multirow[t]{2}{*}{ Total } & \multirow[t]{2}{*}{ Percentage } \\
\hline & Grafton & Jui & Kossoh & & \\
\hline \multicolumn{6}{|c|}{ 8. Are the antimalarial drugs FREE which you and your family took? } \\
\hline Yes, they are free for all & 38 & 12 & 20 & 70 & $26.7 \%$ \\
\hline $\begin{array}{l}\text { No, only for children, } \\
\text { pregnant women and } \\
\text { breast-feeding women }\end{array}$ & 2 & 4 & 3 & 9 & $3.4 \%$ \\
\hline None is FREE & 67 & 31 & 71 & 169 & $64.5 \%$ \\
\hline Don't answer & 1 & 0 & 13 & 14 & $5.3 \%$ \\
\hline \multicolumn{6}{|c|}{$\begin{array}{l}\text { 9. When you and your family were infected with malaria, did you take the full dosage of antimalarial drugs which was prescribed by doctor/health } \\
\text { worker? }\end{array}$} \\
\hline $\begin{array}{l}\text { Yes, take full dosages every } \\
\text { time }\end{array}$ & 93 & 35 & 81 & 209 & $79.8 \%$ \\
\hline $\begin{array}{l}\text { No, sometimes some } \\
\text { dosage was left }\end{array}$ & 15 & 8 & 10 & 33 & $12.6 \%$ \\
\hline $\begin{array}{l}\text { No, some dosages were left } \\
\text { every time }\end{array}$ & 0 & 3 & 1 & 4 & $1.5 \%$ \\
\hline Don't answer & 0 & 1 & 15 & 16 & $6.1 \%$ \\
\hline \multicolumn{6}{|c|}{9.1 If not all drugs taken, please explain why: } \\
\hline $\begin{array}{l}\text { We got recovery before } \\
\text { finishing all of them }\end{array}$ & 15 & 9 & 9 & 33 & $89.2 \%$ \\
\hline $\begin{array}{l}\text { The drugs made me have } \\
\text { headache, nausea }\end{array}$ & 0 & 0 & 0 & 0 & $0.0 \%$ \\
\hline $\begin{array}{l}\text { I am too busy to remember } \\
\text { taking all the dosage }\end{array}$ & 0 & 1 & 1 & 2 & $5.4 \%$ \\
\hline Others: specify & 0 & 1 & 1 & 2 & $5.4 \%$ \\
\hline Don't answer & 0 & 0 & 0 & 0 & $0.0 \%$ \\
\hline
\end{tabular}

"There were two respondents reported taking both Sp/Fansidar and Artesunate + Lumafantrine.

\# There were six respondents in Grafton and three respondents in Kossoh reported taking both Artesunate + Lumafantrine and Artesunate + Amodiaquine.

\& There were three respondents reported taking both Artesunate + Lumafantrine and other.

@ There was one respondent reported taking both Artesunate + Lumafantrine and Artesunate + Amodiaquine and other.

$\$$ There were two respondents reported taking both Artesunate + Lumafantrine and Amodiaquine.

$\%$ There was one respondent reported taking both Artesunate + Lumafantrine and Quinine.

${ }^{\Phi}$ There was one respondent reported taking both Amodiaquine and other.

Sanitation, Sierra Leone, in December 2018, at the midpoint of the SL-NMSP (3). Local staff from Sierra Leone-China Friendship Biological Safety Laboratory (7) were trained in prior to their involvement in the administration of the survey.

\section{Data Analysis}

Data was input and cross-checked by EpiData version $3.1(8,9)$. Then, descriptive statistics and percentages were presented using Microsoft Excel 2010 software. Differences in distribution among three communities were evaluated using the chi-square $\left(\chi^{2}\right)$ test or Fisher's exact test by SPSS software version 20.0 (IBM, USA) and $P<0.05$ was considered statistically significant.

\section{RESULTS}

A total of 300 households were investigated, and 262 qualified questionnaires from 108, 47, and 107 households in Grafton, Jui, and Kossoh communities, respectively, were finally included in the analysis after checking for questionnaire completion and logic. The survey covered 1,645 residents, with $\sim 6$ persons per family. The average cost of meals per day was $\sim 30,000$ Leones in each household (one US dollar was equal to 8,000 Leones in December 2018).

\section{Malaria Infection, Diagnosis, and Treatment}

A total of 929 persons in 202 households reported having had a fever in 2018. Among them, 406 persons from 97 households, 228 persons from 46 households, and 295 persons from 89 households in Grafton, Jui, and Kossoh communities, respectively, reported having suffered malaria. Moreover, 129 persons from 64 households reported having suffered malaria once, and 146 persons from 66 households reported having suffered malaria being twice, and 61 persons from 26 households being three times, and 275 persons from 91 households being more than three times, respectively.

Moreover, $\sim 80.9 \%(212 / 262)$ of the respondents reported seeking professional advice or treatment for the illness from any source $(P<0.001$, Fisher's exact test) (Table 1$)$. Additionally, $72.2 \%(153 / 212)$ of the respondents reported preferring to seek 
TABLE 4 | Malaria prevention practices in the three communities in the Western Area Rural District, Sierra Leone, 2018.

\begin{tabular}{lccc}
\hline Question and answer & Community & Percentage \\
\cline { 2 - 4 } & Grafton & Jui & Kossoh
\end{tabular}

\section{Do you have a mosquito treated bed nets in your home?}

$\begin{array}{lcc}\text { Yes } & 79 & 37 \\ \text { No } & 29 & 10 \\ \text { 2. Did you sleep under a mosquito net last night? } & \\ \text { Yes } & 66 & 25 \\ \text { No } & 36 & 19 \\ \text { Don't answer } & 6 & 3\end{array}$

3. Is there anyone in your household who did not sleep under treated bed nets last night?

$\begin{array}{lccc}\text { Yes } & 69 & 37 & 56 \\ \text { No } & 29 & 7 & 48 \\ \text { Don't answer } & 10 & 3 & 3\end{array}$

\section{Are there enough treated bed nets in your household?}

$\begin{array}{lccc}\text { Yes } & 25 & 8 & 32 \\ \text { No } & 73 & 39 & 73 \\ \text { Don't answer } & 6 & 0 & 2\end{array}$

5. Do all children under $\mathbf{5}$ years in your household sleep under treated bed nets at night?

Yes $\quad 39 \quad 25-38$

$\begin{array}{llll}\text { No } & 26 & 13 & 27\end{array}$

No children under 5

Don't answer 2

\section{Where did you get the treated bed nets?}

Government Hospital/Health 58

Center

Mobile Clinic

Community Health Center

Private Hospital/Clinic

Pharmacy

Shop

Traditional Healer

Others

Don't answer

$58-32^{\star}$

72

35

55

51

1

\section{6}

48

3

32

3

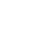

7. Did you spray insecticide to kill mosquitoes in your house?

Often 998

$\begin{array}{lll}\text { Sometimes } & 12 & 13\end{array}$

Seldom $15 \quad 9$

$\begin{array}{lll}\text { Never } & 72 & 17\end{array}$

Don't answer

0

8. Did you spray insecticide to kill mosquitoes outside your house?

$\begin{array}{lcc}\text { Often } & 0 & 1 \\ \text { Sometimes } & 2 & 2 \\ \text { Seldom } & 6 & 38 \\ \text { Never } & 100 & 1\end{array}$

9. Does your house have doors or windows screen which could stop the mosquitoes to go into the house?

$\begin{array}{lccccc}\text { Yes } & 6 & 14 & 38 & 58 & 22.1 \% \\ \text { No } & 102 & 33 & 67 & 202 & 2 \\ \text { Don't answer } & 0 & 0 & 2 & 2.1 \%\end{array}$

$71.8 \%$

$28.2 \%$

$55.7 \%$

$40.5 \%$

$3.8 \%$

$61.8 \%$

$32.1 \%$

$6.1 \%$

$24.8 \%$

$72.1 \%$

$3.1 \%$

$38.9 \%$

$25.2 \%$

$34.4 \%$

$1.5 \%$

$49.6 \%$

$0.4 \%$

$15.3 \%$

$3.1 \%$

$0.4 \%$

$3.8 \%$

$0.0 \%$

$9.9 \%$

$20.2 \%$

$12.6 \%$

$14.1 \%$

$18.3 \%$

$54.6 \%$

$0.4 \%$

$1.9 \%$

$2.3 \%$

$7.6 \%$

$85.9 \%$

$2.3 \%$

$22.1 \%$

$77.1 \%$

$0.8 \%$ 
TABLE 4 | Continued

\begin{tabular}{|c|c|c|c|c|c|}
\hline \multirow[t]{2}{*}{ Question and answer } & \multicolumn{3}{|c|}{ Community } & \multirow[t]{2}{*}{ Total } & \multirow[t]{2}{*}{ Percentage } \\
\hline & Grafton & Jui & Kossoh & & \\
\hline \multicolumn{6}{|c|}{ 10. Do you and your family often stay outside of the house at night (such as for walk, exercises, enjoy the cool air, work, etc) } \\
\hline Often & 57 & 41 & 86 & 184 & $70.2 \%$ \\
\hline Sometimes & 38 & 4 & 9 & 51 & $19.5 \%$ \\
\hline Seldom & 8 & 1 & 6 & 15 & $5.7 \%$ \\
\hline Never & 4 & 1 & 4 & 9 & $3.4 \%$ \\
\hline Don't answer & 1 & 0 & 2 & 3 & $1.1 \%$ \\
\hline
\end{tabular}

"There were six respondents reported taking the treated bed nets from Government Hospital/Health Center and Private Hospital/Clinic both.

\# There was one respondent reported taking the treated bed nets from Government Hospital/Health Center and shop both.

advice and treatment from the public medical sector (including government hospital, government health center, mobile clinic, community health worker, other public sector $)$ only $(P=0.001$, Fisher's exact test). And 20.3\% (43/212) and 7.1\% (15/212) were found to seek assistance from the private sector (including private hospital, private clinic, mission/faith-based hospital, mission/faith-based clinic, pharmacy, mobile clinic, other private medical sector) only or any sector (Tables 1,2 ).

Furthermore, $84.4 \%(221 / 262)$ of the respondents reported that they and their family members always visited a health care worker or doctor when they suspected they had contracted malaria ( $P=0.071$, Fisher's exact test). Among the individuals who went to see a health care worker or doctor, they reported visiting a professional every time $(43.4 \%, 96 / 221)$ or most of the times $(37.1 \%, 82 / 221)$ they suspected they had contracted malaria $\left(\chi^{2}=37.219, P<0.000\right)$ (Table 3$)$.

As recalled by the respondents, the health care worker or doctor performed a malaria test when they visited because they suspected that they had contracted malaria $(80.2 \%, 210 / 262)$ $\left(\chi^{2}=15.854, P=0.003\right)$, and the malaria rapid diagnostic tests (RDT) was the most commonly used test $(54.6 \%, 143 / 262)$; however, approximately half of the respondents $(55.0 \%, 144 / 262)$ reported that the doctors or health care workers did not explain the test to them (Table 3).

Most respondents took anti-malarial medicine every time $(41.2 \%, 108 / 262)$ or almost every time $(35.9 \%, 94 / 262)$ they were diagnosed with malaria, and $\sim 79.8 \%$ (209/262) of them took the full course of treatment every time as prescribed by the doctor or health care worker. Artesunate and lumefantrine (57.6\%, $151 / 262)$ and artesunate and amodiaquine $(20.6 \%, 54 / 262)$ were the top two choices of combination therapy. The most common reason given for the early termination of a course of treatment was having recovered prior to finishing all the doses $(89.2 \%$, $33 / 37)$. Moreover, $\sim 80.2 \%(210 / 262)$ of the respondents reported starting anti-malarial medicine on the same day that they noted the fever, and $\sim 64.5 \%(169 / 262)$ of them responded that the anti-malarial medicine were not free (Table 3 ).

\section{Malaria Prevention Measures}

In this survey, 188 households had long-lasting insecticidal nets (LLINs) $\left(\chi^{2}=2.282, P=0.340\right)$, but more nets were required because 189 respondents said that they did not have enough LLINs in their households $(P=0.102$, Fisher's exact test), so resulting in children under the age of 5 years in 66 households not having LLINs to sleep under $(P=0.120$, Fisher's exact test). Only 146 respondents had slept under nets the night before the survey $(P=$ 0.073 , Fisher's exact test). Furthermore, some members in 162 households with nets did not sleep under LLINs $\left(\chi^{2}\right.$ $=18.179, P=0.001$ ), which could lead to cross-infection. Half of the LLINs were distributed by the governmental hospital/health centers $(49.6 \%, 130 / 262)$ and community health centers (15.3\%, 40/262) (Table 4).

In addition, a total of 143 households never sprayed insecticide indoors to kill mosquitoes $\left(\chi^{2}=19.945, P=\right.$ $0.007)$, and 225 households never sprayed insecticide outside ( $P=0.073$, Fisher's exact test). Furthermore, more than three quarters of the respondents $(77.1 \%, 202 / 262)$ reported that they did not have a door or window screen to prevent mosquitoes from entering their houses $(P<0.001$, Fisher's exact test). Additionally, most families $(89.7 \%, 235 / 262)$ reported staying outside of the house at night $(P<0.001$, Fisher's exact test) (Table 4).

\section{Knowledge of Malaria}

In this survey, almost all the respondents had heard about malaria $(98.1 \%, 257 / 262)(P=0.214$, Fisher's exact test) and knew that the main route of transmission was through mosquito biting $(86.6 \%$, $227 / 262)\left(\chi^{2}=5.045, P=0.081\right)$. Fever $(44.3 \%, 116 / 262)\left(\chi^{2}\right.$ $=4.845, P=0.092)$, body aches or joint pain $(38.9 \%, 102 / 262)$ $\left(\chi^{2}=1.189, P=0.566\right)$, and loss of appetite $(36.6 \%, 96 / 262)\left(\chi^{2}\right.$ $=2.928, P=0.237)$ were the top three clinical manifestations they reported. A total of 173 respondents reported that they would always go to see a doctor or health care worker when they suspected they had malaria $\left(\chi^{2}=1.323, P=0.530\right)$, while 48 interviewees said they would take some of the anti-malarial medicine kept in their houses first $\left(\chi^{2}=15.322, P<0.001\right)$. The expensive costs (mentioned by 176 respondents) was the main factor preventing people from visiting the doctor or health care worker $\left(\chi^{2}=0.059, P=0.969\right)$. Sleeping under LLINs (198) $\left(\chi^{2}\right.$ $=1.432, P=0.499)$ and keeping their surrounding clean $(84)\left(\chi^{2}\right.$ $=5.982, P=0.051)$ were the most common methods of malaria prevention employed (Table 5). 
TABLE 5 | Knowledge of malaria transmission, symptom and prevention in the three communities in the Western Area Rural District, Sierra Leone, 2018.

\begin{tabular}{lc}
\hline Question and answer & Grafton \\
\cline { 2 - 2 } 1. Have you or any member of your family \\
Yes & 107 \\
No & 1 \\
2. In your opinion, what cause malaria?* \\
Mosquito bites & 89 \\
Eating immature sugarcane & 0 \\
Eating dirty food & 6 \\
Drinking beer/palm Wine & 0 \\
Drinking dirty water & 11 \\
Getting soaked with rain & 0 \\
Cold or changing weather & 1 \\
Witchcraft I. injections/drugs & 0 \\
Eating oranges or mangos & 0 \\
Eating plenty oil & 2 \\
Sharing razors/blades & 1 \\
Don't answer & 9
\end{tabular}

\section{Can you tell any symptoms of malaria?*}

Fever 48

Excessive sweating 11

Feeling cold 36

Headache 33

Nausea and vomiting 11

Dizziness 19

Loss of appetite $\quad 35$

Body ache or joint pain $\quad 46$

Body weakness 31

Refusing to eat or drink 0

Jaundice 0

Dark urine 14

Others

Don't answer

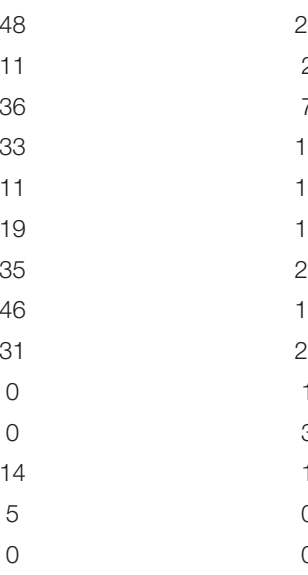

Community

Jui

Kossoh

ness called malaria?

4. What should you do when you suspect getting malaria infection?*

\begin{tabular}{|c|c|c|c|c|c|}
\hline $\begin{array}{l}\text { Must go to see the } \\
\text { doctor/health worker }\end{array}$ & 67 & 32 & 74 & 173 & $66.0 \%$ \\
\hline $\begin{array}{l}\text { Take some anti-malarial } \\
\text { drugs kept in house }\end{array}$ & 26 & 1 & 11 & 48 & $18.3 \%$ \\
\hline $\begin{array}{l}\text { Not necessary to see the } \\
\text { doctor/health worker and } \\
\text { take drugs }\end{array}$ & 3 & 0 & 0 & 3 & $1.1 \%$ \\
\hline $\begin{array}{l}\text { Go to see the doctor/health } \\
\text { worker only when shown } \\
\text { severe condition }\end{array}$ & 2 & 0 & 13 & 15 & $5.7 \%$ \\
\hline Others: Specify. & 9 & 1 & 8 & 18 & $6.9 \%$ \\
\hline Don't answer & 1 & 3 & 3 & 7 & $2.7 \%$ \\
\hline \multicolumn{6}{|c|}{ 5. What are the reasons you think that someone would not go to see the doctor/health worker when he or she gets malaria infection?* } \\
\hline $\begin{array}{l}\text { We are all used to it and no } \\
\text { necessary to see the doctor }\end{array}$ & 0 & 1 & 1 & 2 & $0.8 \%$ \\
\hline $\begin{array}{l}\text { Prayers could make us } \\
\text { recover }\end{array}$ & 0 & 0 & 0 & 0 & $0.0 \%$ \\
\hline $\begin{array}{l}\text { They are strong enough and } \\
\text { could recover even if they } \\
\text { do not see the doctor }\end{array}$ & 0 & 0 & 0 & 0 & $0.0 \%$ \\
\hline
\end{tabular}

(Continued) 
TABLE 5 | Continued

\begin{tabular}{|c|c|c|c|c|c|}
\hline \multirow[t]{2}{*}{ Question and answer } & \multicolumn{3}{|c|}{ Community } & \multirow[t]{2}{*}{ Total } & \multirow[t]{2}{*}{ Percentage } \\
\hline & Grafton & Jui & Kossoh & & \\
\hline $\begin{array}{l}\text { They have anti-malarial } \\
\text { drugs and take it when } \\
\text { necessary }\end{array}$ & 1 & 11 & 7 & 19 & $7.3 \%$ \\
\hline $\begin{array}{l}\text { It is unnecessary to see the } \\
\text { doctor/health worker for } \\
\text { recovering from malaria }\end{array}$ & 1 & 1 & 0 & 2 & $0.8 \%$ \\
\hline $\begin{array}{l}\text { It is too expensive to see the } \\
\text { doctor/health worker }\end{array}$ & 73 & 32 & 71 & 176 & $67.2 \%$ \\
\hline $\begin{array}{l}\text { It is too far to go to see the } \\
\text { doctor/health worker }\end{array}$ & 0 & 1 & 2 & 3 & $1.1 \%$ \\
\hline Other reasons & 33 & 0 & 21 & 54 & $20.6 \%$ \\
\hline Don't answer & 4 & 2 & 7 & 13 & $5.0 \%$ \\
\hline \multicolumn{6}{|c|}{ 6. How can someone protect themselves against malaria?* } \\
\hline Sleep under treated bed net & 78 & 38 & 82 & 198 & $75.6 \%$ \\
\hline Untreated mosquito net & 1 & 0 & 0 & 1 & $0.4 \%$ \\
\hline Use mosquito repellent & 2 & 1 & 1 & 4 & $1.5 \%$ \\
\hline $\begin{array}{l}\text { Use mosquito insecticide } \\
\text { spray (Shelltox) }\end{array}$ & 12 & 5 & 3 & 20 & $7.6 \%$ \\
\hline Take preventive medication & 0 & 9 & 2 & 11 & $4.2 \%$ \\
\hline Indoor residual spray (IRS) & 0 & 3 & 4 & 7 & $2.7 \%$ \\
\hline Use mosquito coils & 7 & 3 & 5 & 15 & $5.7 \%$ \\
\hline Cut grass around house & 6 & 4 & 1 & 11 & $4.2 \%$ \\
\hline Eliminate stagnant water & 8 & 4 & 9 & 21 & $8.0 \%$ \\
\hline Keep surroundings clean & 42 & 9 & 33 & 84 & $32.1 \%$ \\
\hline Don't drink dirty water & 1 & 0 & 2 & 3 & $1.1 \%$ \\
\hline Contaminated food & 3 & 0 & 4 & 7 & $2.7 \%$ \\
\hline $\begin{array}{l}\text { Use mosquito screens on } \\
\text { windows and doors }\end{array}$ & 0 & 1 & 5 & 6 & $2.3 \%$ \\
\hline Others: specify & 14 & 0 & 10 & 24 & $9.2 \%$ \\
\hline Don’t answer & 1 & 1 & 1 & 3 & $1.1 \%$ \\
\hline \multicolumn{6}{|c|}{ 7. Where do you think the mosquito larvae live? DO NOT PROMPT ANSWER } \\
\hline In water & 61 & 33 & 59 & 153 & $58.4 \%$ \\
\hline In weed & 0 & 2 & 2 & 4 & $1.5 \%$ \\
\hline In rubbish & 24 & 6 & 24 & 54 & $20.6 \%$ \\
\hline I don't know & 19 & 0 & 17 & 36 & $13.7 \%$ \\
\hline Don't answer & 4 & 6 & 5 & 15 & $5.7 \%$ \\
\hline
\end{tabular}

*It is a multiple-choice question.

\section{DISCUSSION}

Malaria remains one of the most serious public health issues and is responsible for high proportions of morbidity and mortality in Sierra Leone. In the present study, overall high levels of knowledge regarding the causes of malaria, prevention mechanisms and symptoms, and active seeking of treatment for malaria from health care providers were found among Sierra Leoneans, similar to the results in the MIS 2013 and $2016(2,10)$; these results with regards to knowledge and practices support malaria control (11-13).

Globally, vector control is the most commonly accomplished through the use of LLINs and indoor residual spraying (IRS), with the aim of reducing the transmission by preventing humanvector contact and killing vector mosquitoes $(14,15)$. The goal was for the entire at-risk population to employ preventive measures, including the use of LLINs, IRS and larval source management, by 2017 in Sierra Leone. However, 72.1\% of the respondents required more nets, which may explain the high percentage $(61.8 \%, 162 / 262)$ of households and the high proportion of children under 5 years old who did not sleep under the nets at night according to this survey. This indicates a large gap in obtaining and using nets by the most vulnerable groups who are not benefiting as much as hoped from preventive malaria interventions. Moreover, screens for doors and windows that are cost-effective to install and maintain are a supplementary 
public health intervention to prevent humans from being bitten by mosquito vectors indoors, thereby significantly reducing the transmission of malaria. However, screens seem to have been neglected in the regular malaria control campaigns $(16,17)$, resulting in fewer than $25 \%$ of households having door or window screen in this survey, and a general low awareness of the role of screens. In addition, a low level of implementation of IRS and outside spraying and a high level of engagement in activities outside of the house at night were found, despite the presence of many mosquitoes. Therefore, how to improve residents' outdoor protection, or reduce outdoor activities at night, as well as to further improve the awareness and correct use of protective measures, can become an important content of the future malaria campaign.

The early diagnosis and prompt treatment of malaria reduces the transmission of the disease and prevents deaths. It is critical for people to seek diagnosis and care as soon as they experience any symptoms of malaria. It is encouraging that more than $80 \%$ of the respondents reported that they visited the doctor in a timely manner, and a similar percentage of respondents reported being tested for malaria, usually with RDTs not microscopy, which is the standard method for malaria diagnosis. However, approximately three-quarters of the respondents said that the doctors did not interpret the test results for the patients. Therefore, a good opportunity to provide health education and promote malaria control and prevention is being missed. A home-based RDT that could be performed by trained family members rather than at a healthcare facility may improve the timeliness of the diagnosis of malaria (18-20). Moreover, the reported adherence to completing the course of antimalarial treatment was close to $80 \%$ at the clinic or if self-administration at home. Reasons for the lack of adherence were reported to be sickness after the first dose, insufficient food to take the medicine, forgetting to take the medicine, and poor instructions provided by the community health center (CHC) (21). In addition, the cost of medical treatment and the distance from the hospital must also be considered.

However, there were some limitations of this study. First, this was a small-sample cross-sectional study conducted in three communities, and the findings are not yet nationally representative. Second, the collected data were based on respondent recall, and the data may be biased. Therefore, the results of the study highlight the need for more extensive investigations of the KAP regarding malaria in Sierra Leone.

\section{REFERENCES}

1. World Health Organization. World Malaria Report 2018. Geneva: World Health Organization (2018).

2. Sierra Leone Malaria Indicator Survey. Freetown, Sierra Leone: NMCP, SSL, CRS, and ICF International (2016).

3. Sierra Leone Malaria Control Strategic Plan (2016-2020). Freetown, Sierra Leone: National Malaria Control Programme (2015).

4. Naing PA, Maung TM, Tripathy JP, Oo T, Wai KT, Thi A. Awareness of malaria and treatment-seeking behaviour among persons with acute undifferentiated fever in the endemic regions of Myanmar. Trop Med Health. (2017) 45:31. doi: 10.1186/s41182-017-0070-9

\section{CONCLUSION}

In conclusion, in these three communities, public awareness of malaria prevention measures was relatively high in this survey, but the malaria burden was still higher than because the limited use of preventive measures against malaria potentially. Thus, the existing knowledge of malaria should be sustained and reinforced, and the availability and use of malaria prevention measures should be promoted to achieve the goals of the SL-NMSP.

\section{DATA AVAILABILITY STATEMENT}

The raw data supporting the conclusions of this article will be made available by the authors, without undue reservation.

\section{ETHICS STATEMENT}

The studies involving human participants were reviewed and approved by the Sierra Leone Ethics and Scientific Review Committee. Written informed consent to participate in this study was provided by the participants' legal guardian/next of kin.

\section{AUTHOR CONTRIBUTIONS}

JY and CZ conceived the study, developed questionnaire, and conducted fieldwork. LW and JY analyzed data and wrote the manuscript. SS and BK contributed to the study design. EN and AK conducted fieldwork and supervised fieldwork. XH, XC, XW, and WL contributed to data collation and cross-checking. All authors read and approved the final draft.

\section{FUNDING}

This study was supported by Sierra Leone-China Second Phase of the Fixed Biological Safety Laboratory Technical Cooperation Project and the National Science and Technology Major Program of China (No. 2018ZX10101002-002).

\section{ACKNOWLEDGMENTS}

We appreciate the Sierra Leonean staff for their wonderful work in the Sierra Leone-China Friendship Biological Safety Laboratory.

5. Mathania MM, Kimera SI, Silayo RS. Knowledge and awareness of malaria and mosquito biting behaviour in selected sites within Morogoro and Dodoma regions Tanzania. Malar J. (2016) 15:287. doi: 10.1186/s12936-016-1 $332-4$

6. Alelign A, Petros B. Knowledge, attitudes and practices of malaria transmission and preventive measures in Woreta town, Northwest Ethiopia. BMC Res Notes. (2018) 11:491. doi: 10.1186/s13104-018-3 $607-\mathrm{z}$

7. Wang LL, Wang XC, Pang MF, Hu XQ, Qi XP, Dong XP. The practice of the public health cooperation in the republic of sierra leone: contributions and experiences. China CDC Weekly. (2020) 2:28-31. doi: 10.46234/ccdcw202 0.007 
8. Lauritsen JM, Bruus M. EpiData (Version 3). A Comprehensive Tool for Validated Entry and Documentation of Data. Odense, Denmark: The EpiData Association (2003-2008).

9. Lauritsen JM, Bruus M, Myatt MA. EpiData (Version 1.0-1.5). A Tool for Validated Entry and Documentation of Data. County of Funen Denmark and Brixton Health UK (2001).

10. Sierra Leone Malaria Indicator Survey. Freetown, Sierra Leone: NMCP, SSL, CRS, and ICF International (2013).

11. Yasuoka J, Kikuchi K, Nanishi K, Ly P, Thavrin B, Omatsu T, et al. Malaria knowledge, preventive actions, and treatment-seeking behavior among ethnic minorities in Ratanakiri Province, Cambodia: a community-based cross-sectional survey. BMC Public Health. (2018) 18:1206. doi: 10.1186/s12889-018-6123-0

12. Balami AD, Said SM, Zulkefli NAM, Norsa'adah B, Audu B. Knowledge, motivation, self-efficacy, and their association with insecticidal net use among pregnant women in a secondary health centre in Maiduguri, Nigeria. Malar J. (2018) 17:359. doi: 10.1186/s12936-018-2518-8

13. Moscibrodzki P, Dobelle M, Stone J, Kalumuna C, Chiu YM, Hennig N. Free versus purchased mosquito net ownership and use in Budondo sub-county, Uganda. Malar J. (2018) 17:363. doi: 10.1186/s12936-018-2515-y

14. Bhatt S, Weiss DJ, Cameron E, Bisanzio D, Mappin B, Dalrymple U, et al. The effect of malaria control on Plasmodium falciparum in Africa between 2000 and 2015. Nature. (2015) 526:207-11. doi: 10.1038/nature15535

15. Killeen GF, Smith TA, Ferguson HM, Mshinda H, Abdulla S, Lengeler $\mathrm{C}$, et al. Preventing childhood malaria in Africa by protecting adults from mosquitoes with insecticide-treated nets. PLoS Med. (2007) 4:e229. doi: 10.1371/journal.pmed.0040229

16. Kirby MJ, Ameh D, Bottomley C, Green C, Jawara M, Milligan PJ, et al. Effect of two different house screening interventions on exposure to malaria vectors and on anaemia in children in The Gambia: a randomised controlled trial. Lancet. (2009) 374:998-1009. doi: 10.1016/S0140-6736(09)60871-0
17. Killeen GF, Masalu JP, Chinula D, Fotakis EA, Kavishe DR, Malone D, et al. Control of malaria vector mosquitoes by insecticide-treated combinations of window screens and eave baffles. Emerg Infect Dis. (2017) 23:7829. doi: 10.3201/eid2305.160662

18. Elmardi KA, Malik EM, Abdelgadir T, Ali SH, Elsyed AH, Mudather MA, et al. Feasibility and acceptability of home-based management of malaria strategy adapted to Sudan's conditions using artemisinin-based combination therapy and rapid diagnostic test. Malar J. (2009) 8:39. doi: 10.1186/1475-2875-8-39

19. Thiam S, Thwing J, Diallo I, Fall FB, Diouf MB, Perry R, et al. Scale-up of home-based management of malaria based on rapid diagnostic tests and artemisinin-based combination therapy in a resource-poor country: results in Senegal. Malar J. (2012) 11:334. doi: 10.1186/1475-2875-11-334

20. Ranasinghe S, Ansumana R, Lamin JM, Bockarie AS, Bangura U, Buanie JA, et al. Attitudes toward home-based malaria testing in rural and urban Sierra Leone. Malar J. (2015) 14:80. doi: 10.1186/s12936-015-0582-x

21. Gerstl S, Dunkley S, Mukhtar A, Baker S, Maikere J. Successful introduction of artesunate combination therapy is not enough to fight malaria: results from an adherence study in Sierra Leone. Trans R Soc Trop Med Hyg. (2010) 104:328-35. doi: 10.1016/j.trstmh.2009.12.008

Conflict of Interest: The authors declare that the research was conducted in the absence of any commercial or financial relationships that could be construed as a potential conflict of interest.

Copyright (C) 2021 Wang, Yin, Zheng, Smith, Ngegba, Huang, Kamara, Chen, Wang, Luo and Kan. This is an open-access article distributed under the terms of the Creative Commons Attribution License (CC BY). The use, distribution or reproduction in other forums is permitted, provided the original author(s) and the copyright owner(s) are credited and that the original publication in this journal is cited, in accordance with accepted academic practice. No use, distribution or reproduction is permitted which does not comply with these terms. 